\title{
Ultrastructure of the Effects of Pyrrolidine-fused Chlorins on the Replication of HSV-1
}

António P. A. Matos*, Ana R. N. Santos ${ }^{* *}$, Maria F. Caeiro ${ }^{* *}$, Maria A. F. Faustino ${ }^{* *}$, M. G. P. M. S. Neves ${ }^{* *}$, A. C. Tomé** ${ }^{* *}$ José A. S. Cavaleiro ${ }^{* *}$

*Dental Medical School, University of Lisbon 1649-003 Lisbon and Curry Cabral Hospital, 1069166 Lisbon, Portugal.

** Department of Chemistry, University of Aveiro, 3810-193 Aveiro, Portugal;

*** University of Lisbon, Faculty of Sciences, Department of Plant Biology and Environmental Biology Centre, 1749-016 Lisbon Portugal;

Currently, only few antiviral drugs of proven effectiveness exist against virus of the Herpesviridae family[1,2] and viral resistance to these drugs, especially in the immunocompromised hosts, has encouraged research for new drugs. Some porphyrin derivatives revealed a significant antiviral activity against HSV-1 virus[3]. However the cellular target of the porphyrin derivatives in the viruscell complex remains unknown.

In this work we report results from the ultrastructural evaluation of infected cells treated with two pyrrolidine-fused chlorins (dihydroporphyrins), from a group of seven tested, that showed a significant antiviral activity in the absence of light (Table). These results may render them suitable for systemic use. The compounds showed no cytotoxic effects at the concentration of $5 \mu \mathrm{M}$ used in this study.

The effects of these chlorins against HSV-1 were evaluated by titration of virus grown in Vero cells treated during the reproductive cycle in the absence of light (Graph). Results from the light activated chlorins will be published elsewhere. The cells were processed for transmission electron microscopy from 12 to 24 hours post-infection following standard methods of fixation, embedding and sectioning.

The ultrastructural analysis reveals that, although viral particles are still assembled in the nucleus of infected cells, their distribution is altered. Also, virus-induced alterations of the nuclear membrane are less developed in treated cells (Figs. 1-3). These changes suggest impaired maturation and transport of the virus through the cell. Further studies are needed to evaluate the nature of the target mechanisms at the molecular level.

\section{References}

[1] Roizman, B. In Virology (2nd ed.). Fields, B. N.; Knipe, D. M. (Eds.), Raven Press: New York, 1990, pp 1787-1794.

[2] Kleymann, G., Expert Opin. Invest. Drugs, 12 (2003) 165.

[3] Tomé, J.P.C. et al., Bioorganic \& Medicinal Chemistry, 15 (2007) 4705-4713.

[4] Thanks are due to the University of Aveiro, to Fundação para a Ciência e a Tecnologia (FCT) and FEDER for funding the Organic Chemistry Research Unit. Thanks are due to the University of Lisbon, Faculty of Sciences, Department of Plant Biology for supporting the biological studies. 
Table - Compounds and their inhibitory effects on HSV-1 infection. Inhibition (\%) $\%$ of reduction of virus titer at 24 h.p.i. in treated infected Vero cells relative to the untreated controls.

-NR - Substituted group in the N-pyrrolidine ring of the chlorin.

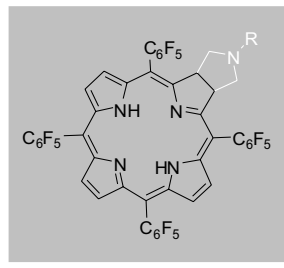

\begin{tabular}{ccc}
\hline Compounds & Inhibition (\%) & -NR \\
\hline 1 & Not done & $-\mathrm{NH}$ \\
\hline 2 & 60 & $-\mathrm{NCH}_{3}$ \\
\hline 3 & 99.7 & $-\mathrm{N}^{\left(\mathrm{CH}_{3}\right)_{2}}$ \\
\hline 4 & 20 & $\mathrm{C}_{12} \mathrm{H}_{19} \mathrm{NO}_{5}$ \\
\hline 5 & 86.3 & $\mathrm{C}_{13} \mathrm{H}_{22} \mathrm{NO}_{5}^{+}$ \\
\hline 6 & 0 & $\mathrm{C}_{6} \mathrm{H}_{11} \mathrm{NO}_{5}$ \\
\hline 7 & 0 & $\mathrm{C}_{7} \mathrm{H}_{14} \mathrm{NO}_{5}{ }^{+}$ \\
\hline
\end{tabular}
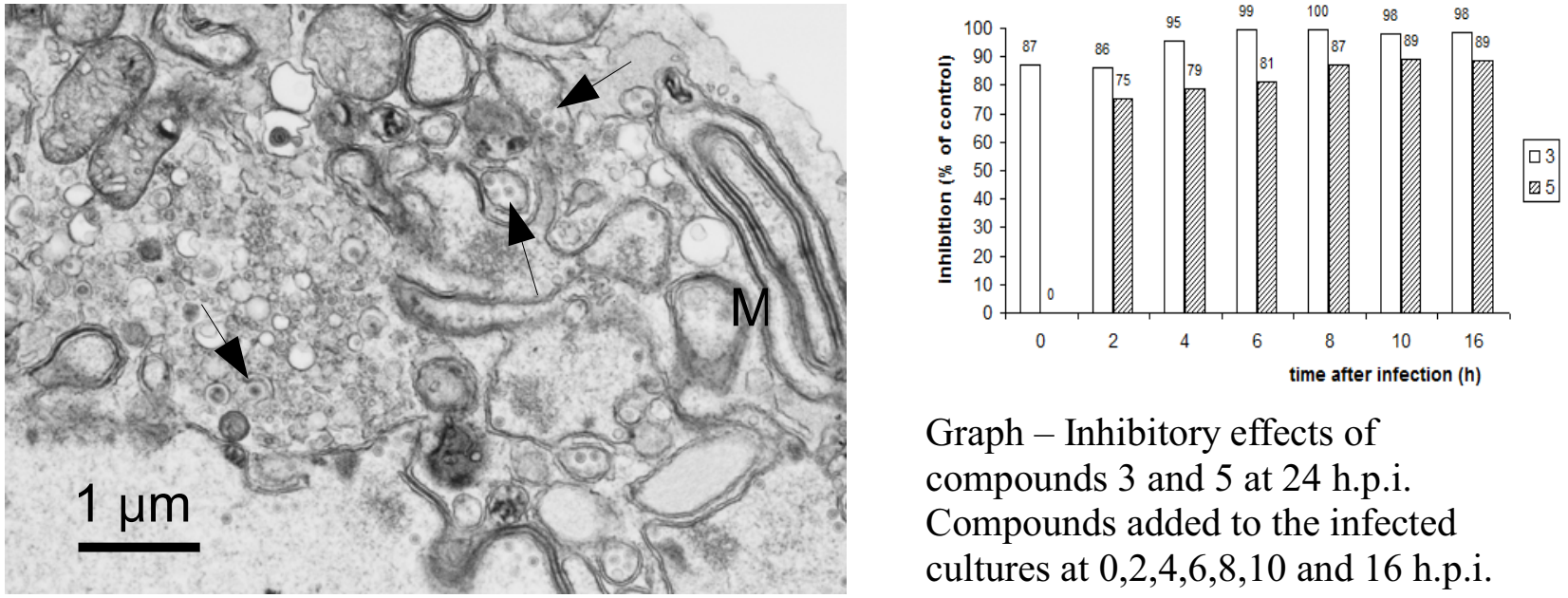

Graph - Inhibitory effects of compounds 3 and 5 at 24 h.p.i.

Compounds added to the infected cultures at $0,2,4,6,8,10$ and 16 h.p.i.

Fig. 1 - HSV-1 infected, untreated Vero cell. M - Alterations of the nuclear membrane. Arrows virions.

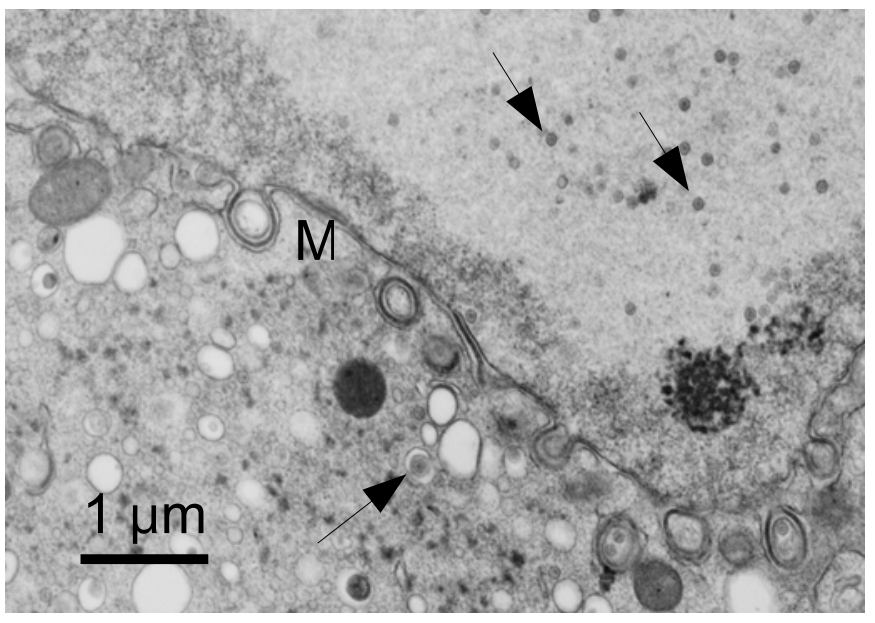

Fig. 2 - HSV-1 infected Vero cell treated with compound 3. M - Nuclear membrane. Arrows - virions.

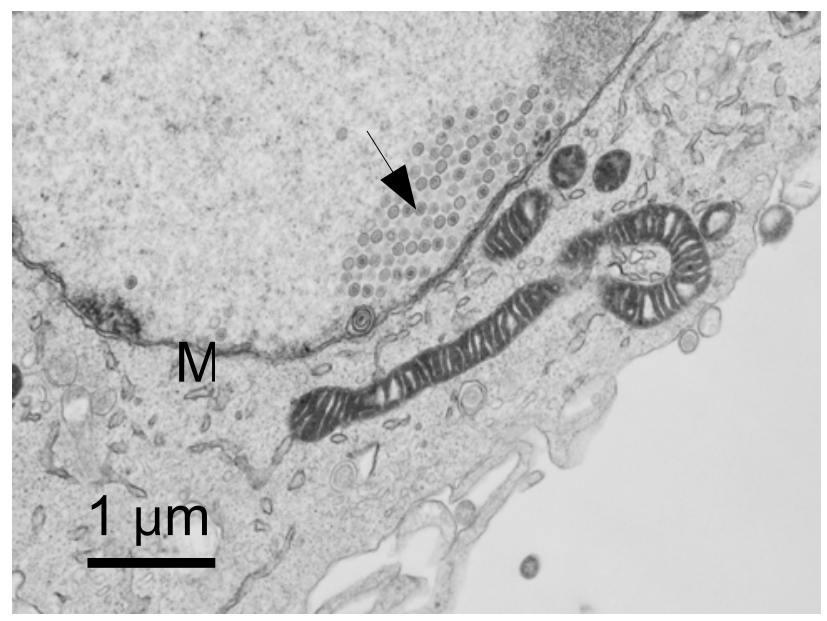

Fig. 3 - HSV-1 infected Vero cell treated with compound 5. M - Nuclear membrane. Arrows - virions. 